\title{
The role of sales effort on manufacturer's channel strategies
}

\author{
Baixun $\mathrm{Li}^{*}$, Guo Chen, and Yaru Nan \\ School of Business Administration, Guangdong University of Finance and Economics, Guangzhou \\ 510320, China
}

\begin{abstract}
Competing manufacturers, who sell their products through retailers, may face the strategic distribution channel design question of whether to establish an "store-within-store" channel or not. With consider of the role of sales effort, we analyze the manufacturer channel strategies. Two cases are considered: competing manufacturer and competing retailer. We built four game models corresponding to four channel strategies, and discussed the influence of manufacture's bargaining power coefficient, prices competition intensity, and sales effort competition intensity on manufactures' channel strategies.
\end{abstract}

\section{Introduction}

Now, the competition form between enterprises gradually evolved into supply chain competition. When supply chains compete on demand, whether enterprises can develop the market and achieve sales and management goals depend on their channel strategies. Especially, "store-within-store" channel is common in realistic, and is a kind of business model that sales products in particular area of a market, which has comprehensive advantages in operation management, customer flow and so on. This business model can take advantages of partners, reduce marketing costs, and break through traditional restrictions on developing the market. At the same time, when enterprises compete on demand, non-price factors such as sales effort level also plays an important role. For example, sales effort, such as laying products on conspicuous shelves, training sales staff, increasing advertising investment, can increase demand. However, if the retailer bears the costs of sales effort alone, it may select the sales effort level which is only good for itself, but may be not good for the manufacture. Thus, manufacture should consider not only how to select channel, but also how to design contract that can stimulate retailer to improve its sales effort behaviors to increase demand and profit and to build a good relationship with the retailer.

The setting of this paper relates to the work on chain-to-chain competition and contract. Zhao and Shi (2011) consider two competing supply chains, which multiple upstream suppliers produce complementary products and sell to a single buyer. Edirisinghe et al. (2011) investigate the implications of channel power on supply chain stability in a setting where multiple suppliers sell substitutable products through a common retailer. Ha et

\footnotetext{
* Corresponding author: libaixun2002qq@163.com
} 
al.(2011) assume imperfect demand signals, production diseconomy, and both Cournot and Bertrand competition with differentiated products. Ai et al. (2012) demonstrate the impact of demand uncertainty and retailers' forecasting precision on contract decisions of the manufacturers in two competing supply chains. Li et al. (2013) explore the effect of supply chain structure and competition at both manufacturer and retailer levels on contract choices of two competing supply chains. Gao et al. (2016) explore the influence of different channel power structures on the optimal decisions and performance of a closed-loop supply chain. Ke and Liu (2017) analyze the dual-channel supply chain in centralized and decentralized cases, and give closed-form expressions for equilibriums in the two cases.

The remainder of this paper is organized as follows. Section 2 presents our model assumption. Section 3 establishes and explores the sub-game solution. Section 4 presents the equilibrium result. Finally, we summarize the paper, and suggest research extensions in Section 5.

\section{Assumption}

Consider a market consisting of two manufacturers $\left(M_{i}, i=1,2\right)$ and two retailers $\left(R_{j}, j=1,2\right)$. Two manufacturers $\left(\mathrm{M}_{1}\right.$ and $\left.\mathrm{M}_{2}\right)$ produce substitute product and sale them through exclusive retailers $\left(R_{1}\right.$ and $\left.R_{2}\right)$. Two manufactures decide whether to select "store-within-store" channel (denoted by S) or traditional distributor channel (denoted by D) at the same time. Therefore there are four structures (SS, DD, SD, and DS). And SS stands for both manufactures select "store-within-store" channels, DD stands for both manufactures select traditional distributor channels, SD or DS stands for one manufacture selects "store-within-store" channel and the other selects traditional distributor channel.

\section{Model}

We built four game models corresponding to four structures (SS, DD, SD, and DS), and discussed each supply chain member's equilibrium decision in each structure. These models study two levels of competition : manufactures level and retailer level. Firstly, we analyse the competition in manufactures level, and assumed demands only influenced by product prices. We built the following demand equation:

$$
D_{i}=1-p_{i}+\theta_{p} p_{j}, i=1,2, j=3-i
$$

Demand and retail price of products in supply chain $i$ are respectively denoted by $D_{i}$ and $p_{i} . \theta_{p}$ is product substitutability, which reflects competition intensity between two supply chains. When $\theta_{p}=0$, two products are independent and there is no competition between two supply chains. When $\theta_{p}=1$, two products can completely substitute each other, and the competition between two supply chains is extremely fierce.

\subsection{DD Structure}

Under this circumstance, both manufactures select traditional distributor channels. Manufactures set wholesale prices at first, and retailers give optimal responds to the given wholesale prices. When wholesale prices of manufactures are given, retailers can decide the optimal retail prices according to the following equation:

$$
\max _{p_{i}^{M D D}>0} \pi_{R i}^{M D D}=\left(p_{i}^{M D D}-w_{i}^{M D D}\right)\left(1-p_{i}^{M D D}+\theta_{p} p_{3-i}^{M D D}\right)
$$


where MDD stands for DD structure that considers competition between manufactures. By the first order condition, we get

$$
p_{i}^{M D D}=\frac{1+w_{i}^{M D D}+\theta_{p} p_{3-i}^{M D D}}{2}
$$

Then, the manufacture's problem is

$$
\max _{w_{i}^{M D D} \geq 0} \pi_{M_{i}}^{M D D}=w_{i}^{M D D} \times d_{i}^{M D D}\left(p_{i}^{* M \mathrm{DD}}\right), \text { By the }
$$

first order condition, we get

$$
w_{i}^{* M D D}=\frac{2+\theta_{p}}{4-\theta_{p}-2 \theta_{p}^{2}} .
$$

According to equilibrium wholesale prices, we can get retail prices, demands, profit functions of retailers and manufactures in all supply chains in MDD structure.

\subsection{SS Structure}

Under this circumstance, both manufactures select "store-within-store" channels. Manufactures sale products and set retail prices. While retailers collect rents ( Fi) as profits. Manufactures' optimization decisions on are as below:

$$
\max _{p_{i}^{M S S} \geq 0} \pi_{M_{i}}^{M S S}=p_{i}^{M S S}\left(1-p_{i}^{M S S}+\theta_{p} p_{3-i}^{M S S}\right)-F_{i}^{M S S} \text {. }
$$

By the first order condition, we can get equilibrium retail prices

$$
p_{i}^{* M S S}=\frac{1}{2-\theta} .
$$

According to equilibrium retail prices and Nash bargaining model, we can get the optimal rents:

$$
\begin{aligned}
\operatorname{Max}\left\{\Phi\left(F_{i}^{M S S}\right)\right\} & =\operatorname{Max}\left\{\left(p_{i}^{{ }^{* M S S}}\left(1-p_{i}^{* M S S}+\theta_{p} p_{3-i}^{* M S S}\right)-F_{i}^{M S S}\right)^{\alpha_{i}}\left(F_{i}^{M S S}\right)^{1-\alpha_{i}}\right\} \\
F_{i}^{M S S} & =\frac{\left(1-\alpha_{i}\right)\left(1+\theta_{p}\right)}{4-\theta_{p}{ }^{2}} \text {. According to } p_{i}^{* M S S} \text { and } F_{i}^{M S S} \text {, we can get }
\end{aligned}
$$

Then, we can get demands, profit functions of retailers in all supply chains in SS structure.

\subsection{SD/DS Structure}

Under these circumstances, one manufacture selects traditional distributor channel (denoted by $\mathrm{SC}_{1}$ )and the other selects "store-within-store" channel (denoted by $\mathrm{SC}_{2}$ ). Taking DS Structure as an example, we can get equilibrium solutions as follow:

$$
\begin{gathered}
w_{1}^{M D S}=\frac{2+\theta_{p}}{2\left(2-\theta_{p}^{2}\right)}, \quad p_{1}^{M D S}=\frac{3-\theta_{p}^{2}}{\left(2-\theta_{p}^{2}\right)\left(2-\theta_{p}\right)} p_{2}^{M D S}=\frac{1+\theta_{p}}{2\left(2-\theta_{p}^{2}\right)}+\frac{1}{2\left(2-\theta_{p}\right)}, \\
F_{2}^{M D S}=\frac{\left(1-\alpha_{2}\right)\left(4+\theta_{p}-2 \theta_{p}^{2}\right)^{2}}{4\left(2-\theta_{p}^{2}\right)^{2}\left(2-\theta_{p}\right)^{2}}
\end{gathered}
$$

As a result, we can get the profit functions of manufactures and retailers in this case. By the same way, we can get the model of competition in retailer level. 
In this part, we studied the equilibrium channels in manufacturers competition situation and retailers competition situation, and we deeply analyzed influence of manufacturers' prices competition and retailers' sales effort levels competition on profit and the equilibrium channels. We identified traditional distributor channel and "store-within-store" channel should be chosen in which conditions. We assumed $\alpha_{1}=\alpha_{2}=\alpha, \eta_{1}=\eta_{2}=\eta, p_{1}^{R}=p_{2}^{R}=3$.

\subsection{The result of competing manufacturers}

To express conveniently, we defined the following functions:

$$
\begin{aligned}
& f_{a}\left(\theta_{p}, \alpha\right)=\pi_{M_{1}}^{M D D}\left(\theta_{p}, \alpha\right)-\pi_{M_{1}}^{M S D}\left(\theta_{p}, \alpha\right) ; f_{b}\left(\theta_{p}, \alpha\right)=\pi_{M_{1}}^{M D S}\left(\theta_{p}, \alpha\right)-\pi_{M_{1}}^{M S S}\left(\theta_{p}, \alpha\right) ; \\
& f_{c}\left(\theta_{p}, \alpha\right)=\pi_{M_{1}}^{M D D}\left(\theta_{p}, \alpha\right)-\pi_{M_{1}}^{M S S}\left(\theta_{p}, \alpha\right) .
\end{aligned}
$$

Obviously, whether all of the function $f_{a}\left(\theta_{p}, \alpha\right), f_{b}\left(\theta_{p}, \alpha\right), f_{c}\left(\theta_{p}, \alpha\right)$ are positive or negative depend on manufacturers prices competition intensity and manufacturers barraging power. We further defined following 4 sets:

$$
\begin{aligned}
& A_{1}=\left\{\left(\theta_{p}, \alpha\right) \mid f_{a}\left(\theta_{p}, \alpha\right)>0, f_{b}\left(\theta_{p}, \alpha\right)>0, f_{c}\left(\theta_{p}, \alpha\right)>0, \text { and } 0<\theta_{p}<1,0<\alpha<1\right\}, \\
& A_{2}=\left\{\left(\theta_{p}, \alpha\right) \mid f_{a}\left(\theta_{p}, \alpha\right)<0, f_{b}\left(\theta_{p}, \alpha\right)>0, f_{c}\left(\theta_{p}, \alpha\right)>0, \text { and } 0<\theta_{p}<1,0<\alpha<1\right\}, \\
& A_{3}=\left\{\left(\theta_{p}, \alpha\right) \mid f_{a}\left(\theta_{p}, \alpha\right)<0, f_{b}\left(\theta_{p}, \alpha\right)<0, f_{c}\left(\theta_{p}, \alpha\right)>0, \text { and } 0<\theta_{p}<1,0<\alpha<1\right\}, \\
& A_{3}=\left\{\left(\theta_{p}, \alpha\right) \mid f_{a}\left(\theta_{p}, \alpha\right)<0, f_{b}\left(\theta_{p}, \alpha\right)<0, f_{c}\left(\theta_{p}, \alpha\right)<0, \text { and } 0<\theta_{p}<1,0<\alpha<1\right\} .
\end{aligned}
$$

Those 4 sets constitute an area $\bigcup_{n=1}^{n=4} A_{n}=\left\{\left(\theta_{p}, \alpha\right) \mid 0<\theta_{p}<1\right.$ and $\left.0<\alpha<1\right\}$ Equilibrium solution in manufacturers competition situation is given in proposition 11-1:

Proposition 1: When two manufactures compete on product prices, if $0<\theta_{p}<1$ and $0<\alpha<1$, two manufactures' equilibrium channels are:

$$
\begin{cases}D D & \text { if } \quad\left(\theta_{p}, \alpha\right) \in A_{1} \\ D S / S D & \text { if } \quad\left(\theta_{p}, \alpha\right) \in A_{2} \\ S S & \text { if } \quad\left(\theta_{p}, \alpha\right) \in A_{3} \cup A_{4}\end{cases}
$$

We can find that area $\left\{\left(\theta_{p}, \alpha\right) \mid 0<\theta_{p}<1,0<\alpha<1\right\}$ is divided into 4 areas by 3 curves (a) $f_{a}\left(\theta_{p}, \alpha\right)=0$, (b) $f_{b}\left(\theta_{p}, \alpha\right)=0$, and (c) $f_{c}\left(\theta_{p}, \alpha\right)=0$. In area $\mathrm{A}_{1}$, two manufactures had better select DD structure, thus DD is not only the unique equilibrium of two manufactures, but also the best selections for them. In area $\mathrm{A}_{2}, \mathrm{DS} / \mathrm{SD}$ structure is the equilibrium of two manufactures. In area $\mathrm{A}_{3}$, SS structure is inferior to DD structure, thus SS structure is only the unique equilibrium of two manufactures, while not the best selections for them. So in this area, two manufactures may fall into prisoners' dilemma if they select SS structure. In area $\mathrm{A}_{4}$, SS structure is not only the unique equilibrium of two manufactures, but also the best selections for them. From the above observation, we can get the following enlightenment, when the bargaining power of manufactures are poor, DD structure (i.e. two manufactures select traditional distributor channels) is the best selection; when the bargaining power of manufactures are strong, SS strategy (i.e. two manufactures select "store-within-store" channel) is the equilibrium. However, this structure may 
induce two manufactures fall into prisoners' dilemma (for example in area $A_{3}$ ) when the competition intensity of product prices is increasing.

\subsection{The result of competing retailers}

We defined the following functions:

$f_{d}\left(\theta_{s}, \alpha\right)=\pi_{M_{1}}^{R D D}\left(\theta_{s}, \alpha\right)-\pi_{M_{1}}^{R S D}\left(\theta_{S}, \alpha\right) ; f_{e}\left(\theta_{s}, \alpha\right)=\pi_{M_{1}}^{R D S}\left(\theta_{s}, \alpha\right)-\pi_{M_{1}}^{R S S}\left(\theta_{s}, \alpha\right) ;$ $f_{f}\left(\theta_{s}, \alpha\right)=\pi_{M_{1}}^{R D D}\left(\theta_{s}, \alpha\right)-\pi_{M_{1}}^{R S S}\left(\theta_{s}, \alpha\right)$.

Obviously, whether all of the function $f_{d}\left(\theta_{s}, \alpha\right), f_{e}\left(\theta_{s}, \alpha\right), f_{f}\left(\theta_{s}, \alpha\right)$ are positive or negative depend on retailers' sales effort levels competition intensity and barraging power. We further defined the following 4 sets:

$$
\begin{gathered}
B_{1}=\left\{\left(\theta_{s}, \alpha\right) \mid f_{d}\left(\theta_{s}, \alpha\right)>0, f_{e}\left(\theta_{s}, \alpha\right)>0, f_{f}\left(\theta_{s}, \alpha\right)>0, \text { and } 0<\theta_{s}<1,0<\alpha<1\right\} ; \\
B_{2}=\left\{\left(\theta_{s}, \alpha\right) \mid f_{d}\left(\theta_{s}, \alpha\right)<0, f_{e}\left(\theta_{s}, \alpha\right)>0, f_{f}\left(\theta_{s}, \alpha\right)>0, \text { and } 0<\theta_{s}<1,0<\alpha<1\right\} ; \\
B_{3}=\left\{\left(\theta_{s}, \alpha\right) \mid f_{d}\left(\theta_{s}, \alpha\right)<0, f_{e}\left(\theta_{s}, \alpha\right)<0, f_{f}\left(\theta_{s}, \alpha\right)>0, \text { and } 0<\theta_{s}<1,0<\alpha<1\right\} ; \\
B_{4}=\left\{\left(\theta_{s}, \alpha\right) \mid f_{d}\left(\theta_{s}, \alpha\right)<0, f_{e}\left(\theta_{s}, \alpha\right)<0, f_{f}\left(\theta_{s}, \alpha\right)<0, \text { and } 0<\theta_{s}<1,0<\alpha<1\right\} .
\end{gathered}
$$

Those 4 sets constitute an area $\bigcup_{n=1}^{n=4} B_{n}=\left\{\left(\theta_{s}, \alpha\right) \mid 0<\theta_{s}<1\right.$ and $\left.0<\alpha<1\right\}$. Equilibrium solution in retailers competition situation is given in Proposition 2:

Proposition 2: When two retailers compete on sales effort levels, if $0<\theta_{s}<1$ and $0<\alpha<1$, two manufactures' equilibrium channels are:

$$
\begin{cases}D D & \text { if } \quad\left(\theta_{p}, \alpha\right) \in B_{1} \\ D S / S D & \text { if } \quad\left(\theta_{p}, \alpha\right) \in B_{2} \\ S S & \text { if } \quad\left(\theta_{p}, \alpha\right) \in B_{3} \cup B_{4}\end{cases}
$$

We find that area $\left\{\left(\theta_{s}, \alpha\right) \mid 0<\theta_{s}<1,0<\alpha<1\right\}$ is divided into 4 areas by 3 curves (d) $f_{d}\left(\theta_{s}, \alpha\right)=0$, (e) $f_{e}\left(\theta_{s}, \alpha\right)=0$, and (f) $f_{f}\left(\theta_{s}, \alpha\right)=0$. In area $\mathrm{B}_{1}$, two manufactures had better select DD structure, thus DD is not only the unique equilibrium of two manufactures, but also the best selections for them. In area $\mathrm{B}_{2}, \mathrm{DS} / \mathrm{SD}$ structure is the equilibrium for two manufactures. In area $\mathrm{B}_{3}$, $\mathrm{SS}$ structure is inferior to DD structure, thus SS structure is only the unique equilibrium of two manufactures, while not the best selections for them. So in this area, two manufactures may fall into prisoners' dilemma if they select SS structure. In area $\mathrm{B}_{4}$, SS structure is not only the unique equilibrium of two manufactures, but also the best selections for them. From the above observation, we can get the following enlightenment: on one hand, similar to manufactures' prices competition situation, when the bargaining power of manufacture are poor, DD structure (i.e. two manufactures select traditional distributor channels) is the best selection; when the bargaining power of manufactures are strong and the sales effort levels competition intensity is low, SS strategy (i.e. two manufactures select "store-within-store" channel) is the equilibrium. However, this structure may induce two manufactures fall into prisoners' dilemma ( for example in area $\mathrm{B}_{3}$ ) when the competition intensity of sales effort levels is increasing. On the other hand, different from manufactures' prices competition situation, when bargaining power of manufactures are strong and sales effort levels competition 
intensity is strong, DD structure are the best selections for manufactures ( for example in area $\mathrm{B}_{1}$ ).

\section{Conclusions}

This paper considers competition between two supply chains. Each supply chain contains a manufacture and a retailer. We assumed demands influenced by prices or sales effort levels of retailers, and each manufacture can select "store-within-store" channel or traditional distributor channel. We built four game models corresponding to four structures (SS, DD, $\mathrm{SD}$, and DS), and discussed the influence of manufacture's bargaining power coefficient, prices competition intensity, and sales effort levels competition intensity on manufactures' selections of channels. Future studies can consider demand uncertainty, human behavior factors, such as risk preference and fairness preference, repeated game model.

\section{Acknowledgement}

This research was supported in part by the National Natural Science Foundation of China under Grants nos. 71401042, the Guangdong Natural Science Foundation under Grants nos. 2014A030313606.

\section{References}

1. Zhao, X. and Shi, C., (2011). Structuring and contracting in competing supply chains. International Journal of Production Economics, 134 (2), 434-446.

2. Edirisinghe, N.C.P., Bichescu, B., and Shi, X., (2011). Equilibrium analysis of supply chain structures under power imbalance. European Journal of Operational Research, $214(2), 568-578$.

3. A. Y. Ha, S. Tong, and H. Zhang, (2011), Sharing demand information in competing supply chains with production diseconomies, Management Science, 57(3), 566-581.

4. X. Ai, J. Chen, and J. Ma, (2012), Contracting with demand uncertainty under supply chain competition, Annals of Operations Research, 201, 17-38.

5. B. X. Li, Y. W. Zhou, J. Z. Li, and S. P. Zhou, (2013), Contract choice game of supply chain competition at both manufacturer and retailer levels, International Journal of Production Economics, 143, 188-197.

6. Gao, J.H., Han, H.S., Hou, L.T. et al. (2016), Pricing and effort decisions in a closed-loop supply chain under different channel power structures. Journal of Cleaner Production, 112, 2043-2057.

7. Ke, H., Liu, J.J.. (2017), Dual-channel supply chain competition with channel preference and sales effort under uncertain environment. Journal of Ambient Intelligence and Humanized Computing, 8(5), 781-795. 